\title{
Say the right thing: Apologies, reputability, and punishment
}

\author{
David B. Wooten \\ Marketing at the Stephen M. Ross School of Business at the University of Michigan, 701 Tappan Street, Ann Arbor, MI 48109-1234, USA \\ Received 23 May 2008; revised 2 February 2009; accepted 12 February 2009 \\ Available online 13 March 2009
}

\begin{abstract}
This research investigates how and when apologies work. Findings from three studies suggest that apologies influence punishment decisions, but not by reducing concerns about recidivism or perceptions of bad intentions. The extent to which future expectancies or perceived intent mediates the effects of apologies on punishment depends on the offender's reputability. However, the perceived appropriateness of the response fully mediates the effect of apologies on punishment, regardless of the offender's reputability. Overall, the findings suggest that saying the right thing helps those who do the wrong thing, but not by influencing others' beliefs about their past intentions or future behaviors.
\end{abstract}

(C) 2009 Society for Consumer Psychology. Published by Elsevier Inc. All rights reserved.

Apologies have become common features of crisis communications (O'Connor, 2004). The proliferation of apologies reflects a philosophical change from the past when experts discouraged them as admissions of guilt or signs of weakness (Frieswick, 2001). Public relations experts attribute this change to lessons learned from Johnson and Johnson's effective response to the Tylenol crisis and President Clinton's ineffective response to the Lewinski affair (Frank, 2000).

In addition to apologies issued on behalf of organizations, they also have been offered by public figures. For instance, radio host, Don Imus, apologized amid public outcry over his reference to the Rutgers University women's basketball team as "nappy-headed hos". Imus fans cited his apology as a reason why he should be forgiven. Critics cited his previous offenses and the nature of this particular one as reasons why he should be fired. He was suspended initially, but fired eventually as the controversy lingered and advertising dollars dwindled (McShane, 2007). More recently, Kelly Tilghman, an anchor on the Golf Channel, apologized to Tiger Woods for commenting that the best way to end his dominance of golf is to "lynch him in a back alley". Despite calls for her dismissal, her employer issued a statement announcing a 2 week suspension for remarks that were inappropriate, but not malicious (Ferguson, 2008). Although her punishment was less severe

E-mail address: dbwooten@umich.edu. than critics demanded; her supporters cited her apology, benign intent, and unblemished past as reasons why she should not have been punished at all.

Although nothing can be concluded from the outcomes of these incidents, something can be inferred from discussions about them in newspapers and blogs. For instance, Imus critics cited past offenses to bolster their claims that he cannot be trusted on the radio. Tilghman supporters compared her innocent gaffe and unblemished past to his hurtful barb and spotted past to argue that the two cases are not alike and, therefore, should be handled differently. The two discussions suggest that: (1) offenders who apologize should be punished less severely than those who do not, (2) the reputability of the offender should moderate the effects of apologies, and (3) the reputability of offenders is influenced by the nature and frequency of their offenses.

Despite the flood of apologies, claims of their effectiveness, and "implicit theories" (e.g., Hung \& Wyer, 2008) about when they work, there have been few examinations of how they operate (e.g., Blodgett et al., 1997; Smith et al., 1999). The present research addresses this gap and attempts to make the following contributions: (1) provide an empirical test of alternative processes through which apologies have been hypothesized to produce their effects, (2) test a useful moderator of various processes and effects, and (3) shed light on consumers' responses to an important element of crisis communications. 


\section{Theoretical background}

\section{Processes and effects}

Apologetic offenders are evaluated more favorably (Darby \& Schlenker, 1982), trusted more readily (Kim et al., 2004), and treated more kindly (Ohbuchi et al., 1989) than their unapologetic counterparts. Schlenker (1980) asserts that apologies gain their effectiveness by performing two interrelated functions: redressing the past and extending a promise of better behavior in the future. These two functions address two major justifications for punishment decisions: retribution and deterrence (McFatter, 1978).

Equity theorists identify many ways by which apologies enable offenders to redress the past and restore equity to their victims. Apologetic offenders can humble themselves and exalt their victims, thereby redistributing esteem and offsetting the emotional sting of their offenses (Walster et al., 1978). The redistribution of shame and power between offenders and victims is a form of compensation for victims (Lazare, 1996). Alternatively, apologetic offenders can express how much they have suffered as a result of their misconduct, thereby causing victims to revise their perceptions of inequity (Walster et al., 1978). Findings that apologies bring about favorable outcomes (Smith et al., 1999) and minimize negative reactions (Blodgett et al., 1997) through their effects on fairness are consistent with this view.

Self-presentation theorists argue that offenders apologize to convince others that their offenses are not true reflections of who they are and, therefore not good predictors of what they will do in the future (Schlenker, 1980). Apologetic offenders split themselves into good and bad selves and blame their offenses on selves that no longer exist or have changed sufficiently to reduce concerns about recidivism (Goffman, 1971). Findings that apologetic offenders are viewed more favorably than unapologetic ones (e.g., Ohbuchi et al., 1989) support the notion that apologies shape perceptions of offenders. Previous studies have not considered how these perceptions affect future expectancies, but Gold and Weiner's (2000) finding that confessions that convey remorse also raise expectations supports the idea that apologies, as admissions of blameworthiness and expressions of remorse, are effective signals of future behavior. The extent to which future expectancies mediate other effects of apologies has not been examined.

An alternative process is suggested by Bennett and Dewberry's (1994) effort to extend Goffman's analysis of facework. Goffman (1967) argued that misconduct threatens identities and disrupts the expressive order. Offenders can save faces and minimize disruptions by engaging in a corrective ritual that includes a challenge, an offering, an acceptance, and an expression of gratitude. The challenge and offering involve calling attention to the misconduct and attempting to correct it. When the offering includes an apology, the offender acknowledges the misconduct and demonstrates awareness of the rules, a commitment to community standards, and worthiness to uphold them. Bennett and Dewberry (1994) argue that normative expectations to accept offerings impose constraints on those who receive them and social costs on those who reject them. They found that victims who reject apologies are viewed less favorably than those who accept them. Evaluations of those who rejected apologies were equally unfavorable regardless of the source's reputability. Moreover, subjects reportedly intended to accept apologies from disreputable sources, despite their desires to reject them.

The theories outlined above suggest different processes by which apologies work. The present article examines the mediating variables implied by these processes and the role of reputability in moderating the effects of apologies.

\section{The moderating role of reputability}

Previous examinations of reputability as a moderator of the effects of apologies have produced mixed results (e.g., Darby \& Schlenker, 1989; Kim et al., 2004). These results and their implications for the present research are summarized below. For the present purposes, reputability is defined as attributions about character based on information about behavior.

Darby and Schlenker (1989) manipulated reputability using descriptions of offenders as friendly, helpful, or trouble prone. They found main effects of apologies and reputability on evaluations and punishment. However, the interaction of apologies and reputability did not affect punishment decisions as expected. They interpreted the finding of only a main effect as evidence that "the apology-forgiveness sequence may be such a familiar script that its appearance automatically benefits the actor" (Darby \& Schlenker, 1989, p. 362). This interpretation suggests that response appropriateness mediates the effects of apologies on punishment decisions. If an apology is called for and offered, then the recipient should accept it (Bennett \& Dewberry, 1994). In this case, reduced punishment is a sign of acceptance.

In an earlier study, Darby and Schlenker (1982) found that response and motives interact to affect evaluations of offenders such that apologies resulted in more favorable evaluations, regardless of motive; but the effect was more pronounced when offenders' motives were good. This finding suggests that apologetic offenders are more likely to avoid negative evaluations as a result of their misconduct as their reputability increases. The authors also found that response and intentionality interacted to affect punishment decisions such that more elaborate apologies resulted in less punishment, but only for accidental offenders. Intentional offenders faced less punishment if they offered apologies, but the benefits of more elaborate apologies were minimal and insignificant. Unlike Darby and Schlenker (1989), reputability moderated the effect of response on punishment decisions in Darby and Schlenker (1982). This difference could be due to differences in the response factor between studies. In the earlier study, the response factor consisted of four levels and included three apology conditions that differed in terms of the elaborateness of the apology, whereas it had only two levels in the later study: a no apology condition and a standard apology condition. The significant interaction found in the earlier study appeared to be driven by the effects of the more elaborate apologies. 
More recently, Kim et al. (2004) found apologies to be more effective than denials at restoring trust for suspected offenders, but only for those accused of ability-related violations as opposed to morality-related violations. Their study did not examine the effects of reputability per se, but their manipulation of violation type was, in effect, a reputability manipulation because of the schemas used to infer traits from the two types of behaviors. Morality-related violations are viewed as diagnostic of morality, but ability-related violations are not seen as diagnostic of ability (Reeder \& Brewer, 1979). Consequently, morality-related violations should prompt more stable and less favorable attributions than should ability-related violations. The findings of Kim et al. (2004) suggest that reputability moderates the effects of apologies on trustworthiness such that apologies are less effective at restoring trust as reputability decreases. Because trust reflects an optimistic expectation about an uncertain event (Hosmer, 1995), these findings suggest that reputability moderates the effects of apologies on future expectancies.

In summary, the notion that reputability moderates the effectiveness of apologies has received mixed support. Studies that support moderation usually find that the effectiveness of apologies increases with reputability. Moreover, this finding appears to emerge with greater consistency when the effect of interest is evaluative as opposed to punitive.

\section{Overview of this research}

Three studies are conducted to test alternative processes by which apologies may operate and to examine reputability as a potential moderator of these processes. Study 1 tests the hypothesis that future expectancies mediate the effect of apologies on need for punishment, but only when the offender is sufficiently reputable. Future expectancies, defined as predictions about future behavior, are similar to "will expectations" (e.g., Boulding et al., 1993). Study 2 reexamines this hypothesis, but with a different reputability manipulation. In addition, it examines response appropriateness as an alternative mediator. Reputability is not expected to moderate the effectiveness of response appropriateness as a mediator of the relationship between apologies and need for punishment. Study 3 reexamines response appropriateness as a mediator of the relationship between apologies and need for punishment. In addition, it considers perceived intent as an alternative mediator. Reputability is manipulated in the three studies by using hypothetical scenarios describing the type of violation committed (Study 1) or the offender's history of committing similar violations (Studies 2 and 3).

Violation type reflects reputability through the schemas people use to infer traits from behaviors. Reeder and Brewer (1979) argue that hierarchically restrictive schemas are used to make inferences about ability and morality traits. With hierarchically restrictive schemas, it is assumed that individuals at a given position on the trait continuum can perform only a range of behaviors at or below a corresponding point on the behavioral continuum. One end of the trait continuum is behaviorally restricted, whereas the other end is not. With ability traits, only the low end is restricted such that people with limited abilities can only perform at low levels (Reeder, 1993). Therefore, knowledge of a skillful performance is sufficient to infer high ability, but knowledge of a poor performance does not necessarily imply inability. With morality traits, only the high end is restricted such that good people are seen as incapable of doing bad (Reeder, 1993). Therefore, a bad deed is diagnostic of low reputability (Skowronski \& Carlston, 1989).

Violation history reflects reputability through the impact of behavioral consistency on trait inferences. Depending on the nature of the behavior and trait involved, knowledge that one often behaves in a particular manner should strengthen inferences about the extent to which the person possesses the corresponding trait (Kelley, 1967). With traits for which partially restrictive schemas apply, behavioral consistency should facilitate dispositional inference (Reeder \& Brewer, 1979). For partially restrictive schemas, it is assumed that actors at a given position on a trait continuum are more likely to perform at the corresponding point on the behavioral continuum than are those at other positions on the trait continuum. As a result, knowledge that one has done multiple deeds that reflect a particular level of behavior (e.g., unfriendly acts) should strengthen beliefs that the actor has a commensurate level of the corresponding trait (e.g., unfriendliness). With traits for which hierarchically restrictive schemas apply, the effect of behavioral consistency on trait inferences depends on which end of the trait continuum is restricted (Reeder \& Brewer, 1979). For morality traits, one immoral deed is sufficient to prompt inferences of immorality (Skowronski \& Carlston, 1989). However for ability traits, many poor performances are necessary to prompt inferences of inability. Therefore, behavioral consistency should facilitate inferences about ability traits.

\section{Study 1}

This study examines future expectancies as a mediator of the effect of apologies on the need to punish offenders, and reputability as a moderator of this effect. Reputability is manipulated using hypothetical scenarios describing the type of violation committed. For simplicity, ability-related violations are called mistakes and morality-related violations are called misdeeds. For mistakes as opposed to misdeeds, correspondence between the behavior and trait should be lower and less enduring (Reeder \& Coovert, 1986), efforts to discount the evaluative implications and predictive validity of offenses should be more effective, and apologies should be more likely to operate through their effects on future expectancies.

\section{Method}

\section{Design}

A study with a 2 (violation type: misdeed vs. mistake) $\times 2$ (apology: yes vs. no) between-subjects design was conducted using hypothetical scenarios adapted from Kim et al. (2004). The scenarios involve an accountant and his manager discussing the results of an audit that revealed irregularities in a few tax reports filed by the accountant. 
Violation type, as an indicator of reputability, was manipulated by varying the manager's justification for conducting the audits and the accountant's response to the audit findings. In the misdeed conditions, the manager explained that audits were used to detect intentional violations of tax codes and to minimize the potential for fraudulent reporting to tarnish the firm's reputation for integrity. The accountant responded to the audit findings by admitting that client demands affected his judgment. In the mistake conditions, the manager explained that audits were used to ensure that accountants had adequate knowledge of tax codes and to minimize the potential for errant reporting to tarnish the firm's reputation for quality. The accountant responded to the audit findings by suggesting that client demands affected his performance. This manipulation was pretested on 24 students whose ratings of the offenders portrayed in the scenarios $\left(M_{\text {mistake }}=2.85, M_{\text {misdeed }}=1.15\right.$; $t=10.74, p<.001)$, using a two item reputability index (measured on a five-point scale) $(\alpha=.77)$, support the use of violation type as an indicator of reputability.

The apology factor was manipulated by varying the accountant's response to the audit findings. In the apology condition, the accountant expressed chagrin, apologized for his performance, and promised to be more careful in the future. In the no apology condition, the accountant described the situation as awkward, did not know what to say about his performance, but promised to be more careful in the future.

\section{Procedures}

Two hundred undergraduate students participated in this study as part of a course requirement. Participants were randomly assigned to conditions and given booklets containing a hypothetical scenario and a brief questionnaire. The questionnaire was used to assess comprehension of details and reactions to the incident reported in the scenario. It included four measures of future expectancies $(\alpha=.76)$ and five measures of need for punishment $(\alpha=.83)$. All items were measured on a seven-point, agree/disagree scale. Means and standard deviations are reported in Table 1.

Results

\section{Comparisons of means}

Separate $2 \times 2$ ANOVAs were conducted to assess the effects of apology and violation type on future expectancies and need for punishment. The results reveal significant main effects of apology $\left(M_{\text {apology }}=4.37, M_{\text {no apology }}=3.98 ; F(1,196)=8.23\right.$, $p<.005)$ and violation type $\left(M_{\text {mistake }}=4.41, M_{\text {misdeed }}=3.94 ; F\right.$

Table 1

Study 1: means of proposed mediator and dependent variable by condition

\begin{tabular}{llllll}
\hline & \multicolumn{2}{l}{ Mistake (more reputable) } & & \multicolumn{2}{l}{ Misdeed (less reputable) } \\
\cline { 2 - 3 } \cline { 6 - 7 } & Apology & No apology & & Apology & No apology \\
\hline Future expectancies & $4.76(0.99)$ & $4.07(0.88)$ & & $3.99(1.09)$ & $3.89(0.92)$ \\
Need for punishment & $3.34(1.06)$ & $4.00(0.91)$ & & $4.27(1.18)$ & $4.53(0.92)$ \\
\hline
\end{tabular}

Note. 50 participants per cell. Standard deviations are given in parentheses.
Mistakes (More Reputable)

Proposed Mediator $=$ Future Expectancies

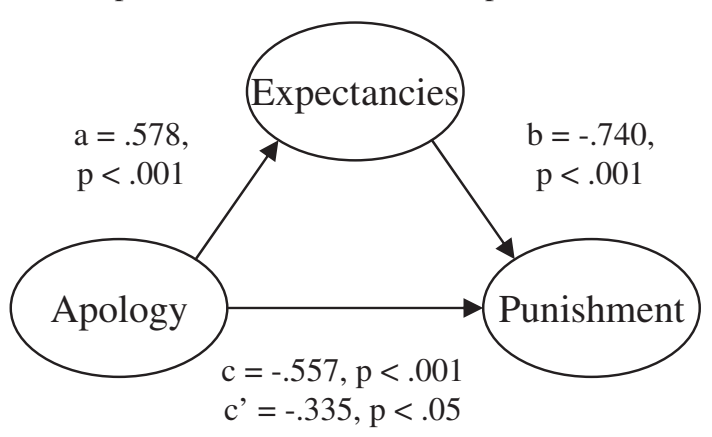

Misdeeds (Less Reputable)

Proposed Mediator $=$ Future Expectancies

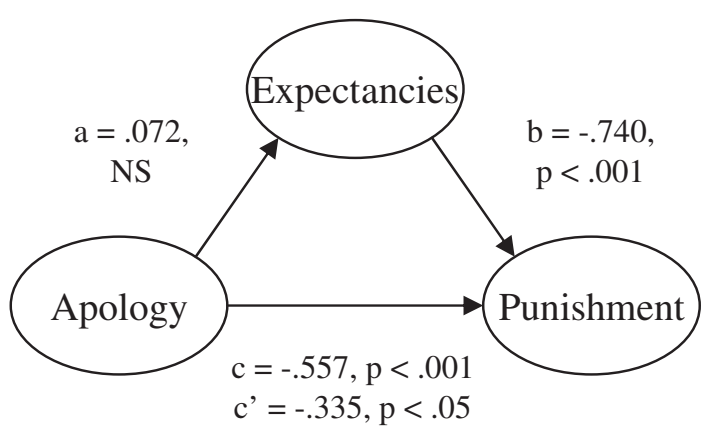

Moderation: $\quad x^{2}(1)=4.09, \mathrm{p}<.05$

Mediation: $\quad \mathrm{Z}=2.90, \mathrm{p}<.005$

Fig. 1. Moderated mediation analysis for Study 1.

$(1,196)=11.91, p<.001)$ on future expectancies. Participants had more favorable expectations of apologetic offenders or those who made mistakes than of unapologetic offenders or those who committed misdeeds. The main effects of apology and violation type were qualified by a significant apology $x$ violation type interaction $(F(1,196)=4.44, p<.05)$. Apologies led to higher future expectancies, but only when issued after mistakes $\left(M_{\text {apology }}=4.76, M_{\text {no apology }}=4.07 ; t=3.52, p<.001\right)$. Participants also had higher expectations of those who made mistakes than of those who committed misdeeds, but only if they apologized $\left(M_{\text {mistake }}=4.76, M_{\text {misdeed }}=3.99 ; t=3.93\right.$, $p<.001)$.

The results also reveal significant main effects of apology $\left(M_{\text {apology }}=3.80, M_{\text {no apology }}=4.26 ; F(1,196)=10.09, p<.005\right)$ and violation type $\left(M_{\text {mistake }}=3.67, M_{\text {misdeed }}=4.40 ; F(1,196)=\right.$ $25.83, p<.001)$ on need for punishment. Participants indicated less need to punish apologetic offenders than unapologetic ones. This effect was significant only for offenders who apologized for mistakes $\left(M_{\text {apology }}=3.34, M_{\text {no apology }}=4.00 ; t=3.22\right.$, $p<.001)$, not for those who apologized for misdeeds $\left(M_{\text {apology }}=4.27, M_{\text {no apology }}=4.53 ; t=1.27\right.$, ns. $)$. The apology $\times$ violation type interaction was not significant. Overall, the pattern of findings from the ANOVAs is consistent with the hypothesis of moderated mediation. 


\section{Test of moderated mediation}

Moderated mediation was tested by conducting a multigroup analysis of a structural model that included only the effects needed to assess mediation. This approach was used to correct for attenuation due to measurement error. The analysis involved two stages. First, moderation was assessed by comparing the model with the effects of interest constrained to be equal between conditions $\left(\chi^{2}(76)=\right.$ $136.21, p<.001)$ to the model with the effect of apologies on future expectancies allowed to differ between conditions $\left(\chi^{2}(75)=132.14, p<.001\right)$. The improvement in fit by allowing the path from apologies to future expectancies to differ between conditions was sufficient to justify the lost degree of freedom $\left(\chi^{2}(1)=4.07, p<.05\right)$. Therefore, moderation is supported.

Second, mediation was assessed using relevant path coefficients from the model favored by the chi-square difference test. In the mistake conditions, apologies led to higher future expectancies $(B=.578, p=.001)$ which decreased the need for punishment $(B=-.740, p<.001)$. The direct effect of apologies on need for punishment $(B=-.557, p<.001)$ was reduced significantly by controlling for future expectancies (Sobel's $Z=2.90, p<.005)$, but the effect remained significant $(B=$ $-.335, p<.05)$. These results suggest that future expectancies only partially mediate the effects of apologies on the need to punish those who make mistakes. In the misdeed conditions, mediation was not supported because apologies had no effect on future expectancies $(B=.072$, ns.). Overall, these results, illustrated in Fig. 1, support the hypothesis of moderated mediation.

\section{Discussion}

This study supports the hypothesis of moderated mediation. Apologies enabled more reputable offenders to avoid punishment by assuring others of better behavior in the future, but this effect did not occur for less reputable offenders. The finding that apologies from those who commit misdeeds are not credible assurances of better behavior in the future is consistent with findings that impressions of immorality are hard to revise (Reeder \& Coovert, 1986). Nonetheless, offenders who apologized were perceived to be less deserving of punishment than were their unapologetic counterparts, regardless of their reputability. The finding that even disreputable offenders who apologize avoid some of the consequences of their actions despite their inability to give credible assurances of better behavior in the future is consistent with previous findings and supports the notion that "the apology-forgiveness sequence may be such a familiar script that its appearance automatically benefits the actor" (Darby \& Schlenker, 1989, p. 362).

An initial goal of this research was to examine conditions under which apologies work through their effect on future expectancies. However, the findings that future expectancies only partially mediate the effect of apologies on the need to punish the offender and that this effect occurs only when the apologetic offender is sufficiently reputable suggest that assuring others of better behavior in the future is neither necessary nor sufficient for apologies to reduce the need for punishment. As a result, Studies 2 and 3 consider alternative mediating variables.

\section{Study 2}

Study 2 reexamines reputability as a moderator of the extent to which future expectancies mediate the effect of apologies on need for punishment, but uses a different reputability manipulation than was used in Study 1. Study 2 also examines response appropriateness as an alternative mediator of the relationship between apologies and punishment. In hypothetical scenarios, offenders are characterized as either first offenders (more reputable) or repeat offenders (less reputable). For first offenders as compared to repeat offenders, correspondence between the behavior and related trait should be lower (Reeder $\&$ Brewer, 1979), efforts to discount the evaluative implications and predictive validity of offenses should be more effective, and apologies should be more likely to operate through their effects on future expectancies. Response appropriateness was identified as a potential mediator based on previous work suggesting that recipients of apologies incur an obligation to accept them and a cost of rejecting them (e.g., Bennett \& Dewberry, 1994). Reputability is not expected to moderate the extent to which response appropriateness mediates the effect of apologies on need for punishment.

\section{Method}

\section{Design}

A study with a 2 (violation history: first offender vs. repeat offender) $\times 2$ (apology: yes vs. no) between-subjects design was conducted using hypothetical scenarios involving a cashier who was accused of being rude to a customer.

Violation history, as an indicator of reputability, was manipulated by characterizing the incident as either the first complaint against the cashier or not. A comparison of mean reputability ratings from a pretest conducted on 24 students $\left(M_{\text {first offense }}=2.50, M_{\text {repeat } \text { offense }}=1.17 ; t=9.31, p<.001\right)$ supports the use of violation history as an indicator of reputability. The apology factor was manipulated by either including the words "I'm sorry" in the cashier's response to the allegation or not.

\section{Procedure}

One hundred sixty-two undergraduates participated in this study to fulfill a course requirement. Participants were randomly assigned to conditions and given booklets containing a hypothetical scenario and a brief questionnaire. The questionnaire was used to assess comprehension of details and reactions to the incident reported in the scenario. It included four measures of future expectancies $(\alpha=.95)$, four measures of response appropriateness $(\alpha=.93)$, and five measures of need for punishment $(\alpha=.83)$. All items were measured using a seven-point, agree/disagree scale. Means and standard deviations are reported in Table 2. 
Table 2

Study 2: means of proposed mediators and dependent variable by condition

\begin{tabular}{|c|c|c|c|c|}
\hline & \multicolumn{2}{|c|}{ First offender (more reputable) } & \multicolumn{2}{|c|}{ Repeat offender (less reputable) } \\
\hline & Apology & No apology & Apology & No apology \\
\hline Future expectancies & $5.01(0.89)$ & $4.28(1.31)$ & $2.73(0.98)$ & $2.81(0.92)$ \\
\hline Response appropriateness & $5.19(1.06)$ & $4.04(1.50)$ & $4.13(1.44)$ & $3.22(1.27)$ \\
\hline Need for punishment & $3.14(0.98)$ & $3.69(1.02)$ & $4.27(1.21)$ & $4.77(0.73)$ \\
\hline
\end{tabular}

Note. 40 participants per cell in first offender conditions and 41 per cell in repeat offender conditions. Standard deviations are given in parentheses.

Results

\section{Comparisons of means}

Separate $2 \times 2$ ANOVAs were conducted to assess the effects of apology and violation history on the proposed mediating and dependent variables. The results reveal significant main effects of apology $\left(M_{\text {apology }}=3.86, M_{\text {no apology }}=3.53 ; F(1,158)=4.07\right.$, $p<.05)$ and violation history $\left(M_{\text {repeat offense }}=2.77, M_{\text {first offense }}=\right.$ $4.64 ; F(1,158)=131.76, p<.001)$ on future expectancies. Participants had more favorable expectations of apologetic or first offenders than of unapologetic or repeat offenders. The main effect of apology was qualified by a significant apology $\times$ violation history interaction $(F(1,158)=6.27, p<.05)$ such that apologies led to higher future expectancies, but only when issued by first offenders $\left(M_{\text {apology }}=5.01, M_{\text {no apology }}=\right.$ 4.28; $t=3.18, p<.005)$.

The results also show significant main effects of apology $\left(M_{\text {apology }}=4.65, M_{\text {no apology }}=3.63 ; F(1,158)=24.27, p<.001\right)$ and violation history $\left(M_{\text {repeat offense }}=3.68, M_{\text {first offense }}=4.62 ; F\right.$ $(1,158)=20.19, p<.001)$ on response appropriateness. Participants indicated that the chosen response was most appropriate when it included an apology or it followed a first offense. The apology $\times$ violation history interaction was not significant.

The results also reveal significant main effects of apology $\left(M_{\text {apology }}=3.71, M_{\text {no apology }}=4.23 ; F(1,158)=11.26, p<.001\right)$ and violation history $\left(M_{\text {repeat offense }}=4.52, M_{\text {first offense }}=3.41 ; F\right.$ $(1,158)=49.61, p<.001)$ on need for punishment. Participants expressed a greater need to punish unapologetic or repeat offenders than to punish apologetic or first offenders. The apology $\times$ violation history interaction was not significant. The pattern of findings from the ANOVAs is consistent with the notion that reputability (based on violation history) moderates the extent to which future expectancies mediates the relationship between apologies and need for punishment. However, it does not appear to moderate the mediating role of response appropriateness.

\section{Tests of moderated mediation}

For future expectancies, the model with the effects of interest constrained to be equal across conditions $\left(\chi^{2}(76)=95.41\right.$, $p=.066$ ) was compared to the model for which the path from apologies to future expectancies differed between conditions $\left(\chi^{2}(75)=89.85, p=.116\right)$. The improvement in fit by allowing the path from apologies to future expectancies to differ was sufficient to justify the lost degree of freedom $\left(\chi^{2}(1)=5.56\right.$, $p<.05)$. Therefore, violation history moderated the effect of apologies on future expectancies. In the first offender condi- tions, apologies resulted in higher future expectancies $(B=.658$, $p<.005)$, which decreased the need for punishment $(B=-.476$, $p<.001)$. The direct effect of apologies on need for punishment $(B=-.673, p<.001)$ was reduced significantly by controlling for future expectancies (Sobel's $Z=2.38, p<.05$ ), but the effect remained significant $(B=-.526, p<.005)$. Therefore, future expectancies only partially mediated the effects of apologies on the need to punish first offenders. In the repeat offenders conditions, mediation was not supported because apologies had no effect on future expectancies $(B=-.066$, ns.). Overall, the results, illustrated in Fig. 2, support the hypothesis of moderated mediation and replicate the results of Study 1.

For response appropriateness, the chi-square difference test $\left(\chi^{2}(1)=.60\right.$, ns. $)$ did not reveal a significant difference between the model for which the path from apologies to response appropriateness differed between conditions $\left(\chi^{2}(75)=152.81\right.$, $p<.001)$ and the one with the effects of interest constrained to be equal between conditions $\left(\chi^{2}(76)=143.41, p<.001\right)$. Therefore, violation history does not appear to moderate the effect of apologies on response appropriateness. For both conditions, apologies had a positive effect on response appropriateness $(B=.985, p<.001)$, which had a negative effect on need for punishment $(B=-.509, p<.001)$. The direct effect of apologies on need for punishment $(B=-.673, p<.001)$ was reduced significantly (Sobel's $Z=3.80, p<.001$ ) and was no longer significant $(B=-.205$, ns.) after controlling for response appropriateness. Therefore, response appropriateness fully mediated the effect of apologies on need for punishment.

\section{Discussion}

Findings from this study replicate findings from Study 1. Apologetic offenders with more favorable reputations (i.e., fewer offenses) were thought to need less punishment than their unapologetic counterparts, partly because they gave more credible assurances of better behavior in the future. However, the mediating effect of future expectancies did not hold for apologetic offenders with a history of bad behavior. This result suggests that apologies may not be effective signals of future intentions when stronger signals (e.g., past behavior) are available. The finding that apologies resulted in less need to punish disreputable (repeat) offenders despite having no effect on future expectancies suggests that an alternative process may be operating. Taken together, the findings of moderated mediation, but only partial mediation, and a significant effect of apologies on need for punishment even in the low reputability (repeat offense) conditions suggest that future 
First Offense (More Reputable)

Proposed Mediator $=$ Future Expectancies

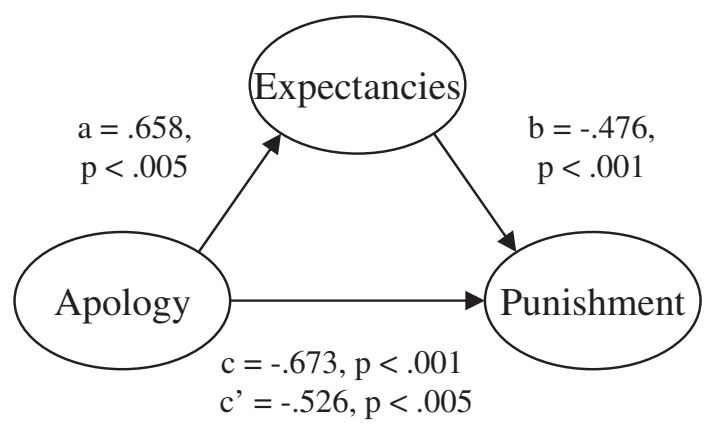

\section{Repeat Offense (Less Reputable)}

Proposed Mediator $=$ Future Expectancies

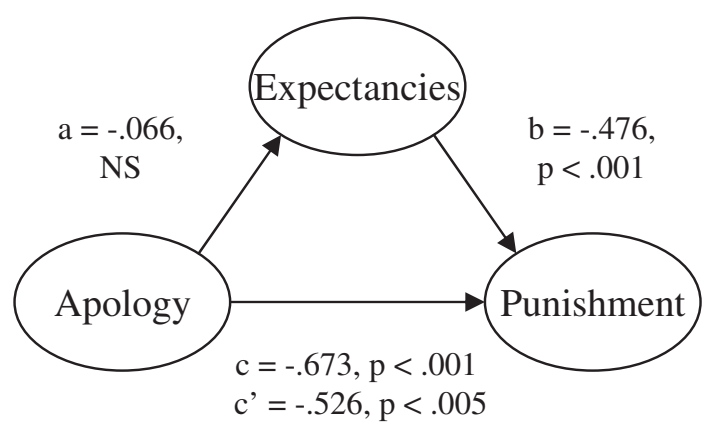

Moderation: $\quad x^{2}(1)=5.56, \mathrm{p}<.05$

Mediation: $\quad \mathrm{Z}=2.38, \mathrm{p}<.05$
First Offense (More Reputable)

Proposed Mediator $=$ Response Appropriateness

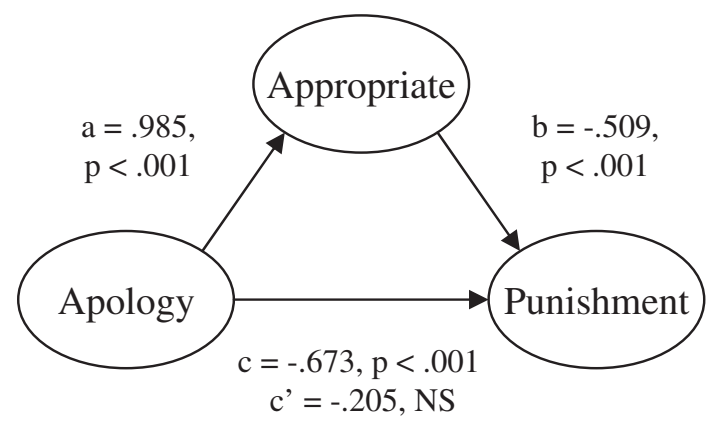

Repeat Offense (Less Reputable)

Proposed Mediator $=$ Response Appropriateness

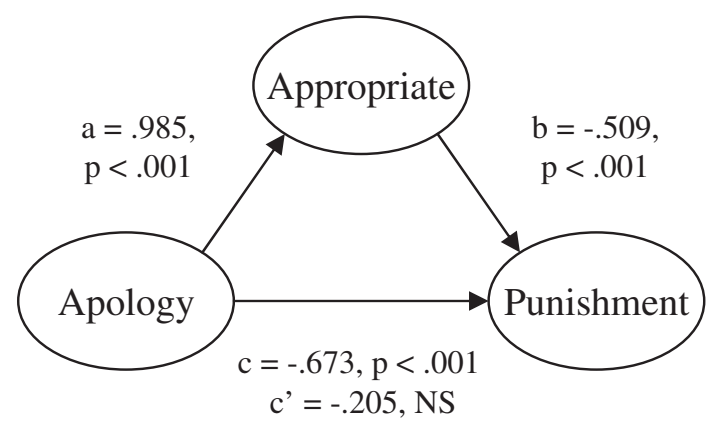

Moderation: $\quad x^{2}(1)=0.60, \mathrm{NS}$

Mediation: $\quad \mathrm{Z}=3.80, \mathrm{p}<.001$

Fig. 2. Moderated mediation analyses for Study 2.

expectancies is neither a necessary nor sufficient mediator of the effect of apologies on need for punishment. Response appropriateness, on the other hand, fully mediated the effect of apologies on need for punishment across conditions. This finding is consistent with findings from previous research (e.g., Bennett \& Dewberry, 1994; Darby \& Schlenker, 1989).

\section{Study 3}

The purpose of this study is twofold. First, it reexamines response appropriateness as a mediator of the effect of apologies on need for punishment. Second, it considers perceived intent as an alternative mediator of the relationship between apologies and need for punishment. Darby and Schlenker (1989) found that offenses by remorseful actors are less likely to be seen as intentional than those by unremorseful actors. The offender's reputation did not moderate this effect. It is possible that apologies, as expressions of remorse, operate through their effects on perceived intent. That is, perceived intent mediates the effect of apologies on need for punishment, regardless of actor's reputability.

\section{Method}

Design

A study with a 2 (violation history: first offender vs. repeat offender) $\times 2$ (apology: yes vs. no) between-subjects design was conducted using hypothetical scenarios about a customer service representative who made a billing error as a result of an incorrect data entry.

Violation history was manipulated by providing information about previous mistakes. Participants were told either that the incident was "his first mistake in a long time" or that "he has made other mistakes recently". A comparison of mean reputability ratings from a pretest conducted on 24 students $\left(M_{\text {first offense }}=3.50, M_{\text {repeat offense }}=2.19 ; t=7.29, p<.001\right)$ supports the use of violation history as an indicator of reputability. For the apology factor, participants were told that the service provider either contacted the customer, apologized for his carelessness, corrected the mistake, and assured the customer of better service in the future or he contacted the customer, corrected the mistake, and assured the customer of better service in the future. 
Table 3

Study 3: means of proposed mediators and dependent variable by condition

\begin{tabular}{|c|c|c|c|c|}
\hline & \multicolumn{2}{|c|}{ First offender (more reputable) } & \multicolumn{2}{|c|}{ Repeat offender (less reputable) } \\
\hline & Apology & No apology & Apology & No apology \\
\hline Response appropriateness & $6.11(0.66)$ & $5.31(0.96)$ & $5.55(1.00)$ & $4.88(1.23)$ \\
\hline Need for punishment & $1.97(0.75)$ & $2.54(0.99)$ & $3.40(1.05)$ & $3.99(1.13)$ \\
\hline
\end{tabular}

Note. 54 participants per cell. Standard deviations are given in parentheses.

\section{Procedure}

Two hundred sixteen participants completed this study either for payment or as part of a course requirement. Participants were randomly assigned to conditions and given booklets containing a hypothetical scenario and a brief questionnaire. The questionnaire was used to assess comprehension of details and reactions to the incident reported in the scenario. It included four measures of response appropriateness $(\alpha=.82)$, four measures of perceived intent $(\alpha=.66)$, and three measures of need for punishment $(\alpha=.82)$. All items were measured on a seven-point, agree/disagree scale. Means and standard deviations are reported in Table 3.

First Offense (More Reputable)

Proposed Mediator $=$ Response Appropriateness

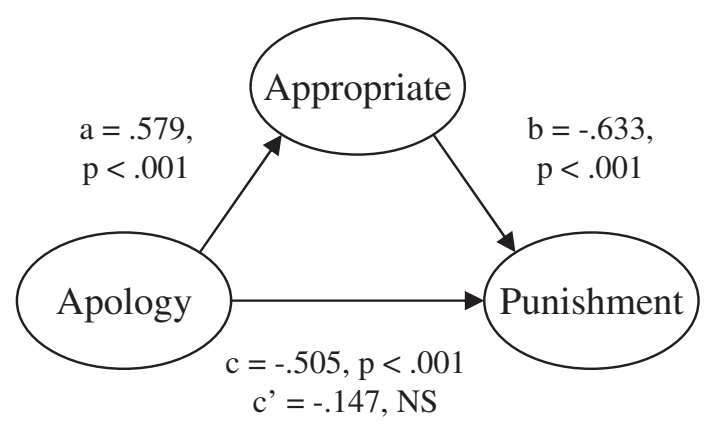

Repeat Offense (Less Reputable)

Proposed Mediator $=$ Response Appropriateness

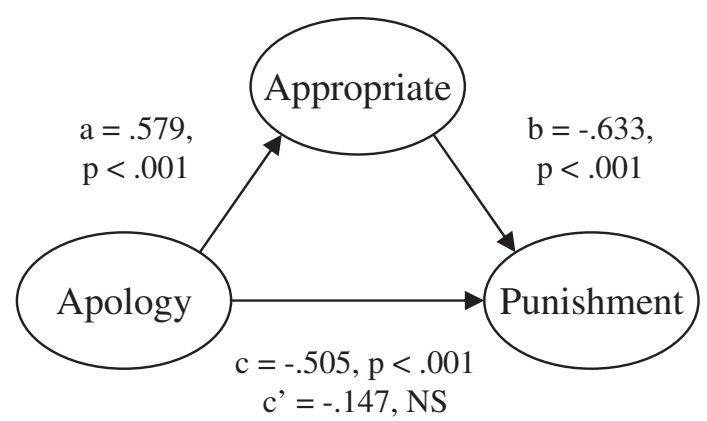

Moderation: $\quad x^{2}(1)=0.30, \mathrm{NS}$

Mediation: $\quad \mathrm{Z}=4.05, \mathrm{p}<.001$

\section{Results}

\section{Comparisons of means}

Results of separate $2 \times 2$ ANOVAs reveal significant main effects of apologies $\left(M_{\text {apology }}=5.83, M_{\text {no apology }}=5.09 ; F(1\right.$, $212)=30.16, p<.001)$ and violation history $\left(M_{\text {repeat offense }}=5.21\right.$, $\left.M_{\text {first offense }}=5.71 ; F(1,212)=13.67, p<.001\right)$ on response appropriateness. Responses that included apologies or followed first offenses were perceived to be more appropriate than responses without apologies or responses from repeat offenders. The apology $\times$ violation history interaction was not significant.



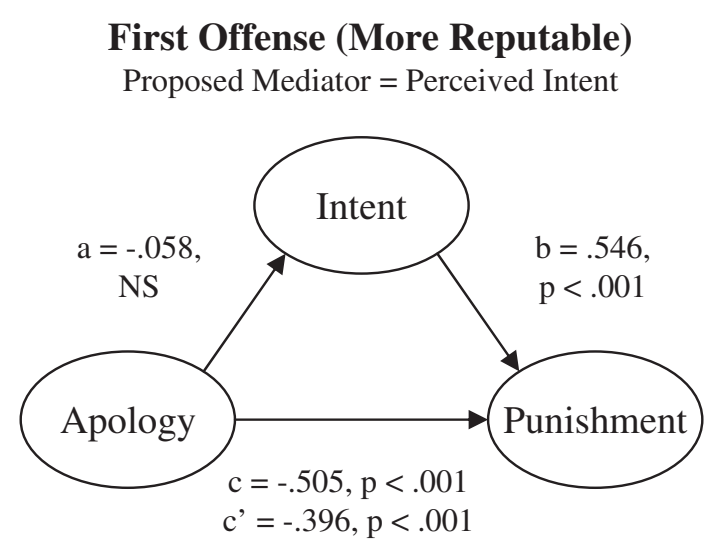

Repeat Offense (Less Reputable)

Proposed Mediator $=$ Perceived Intent

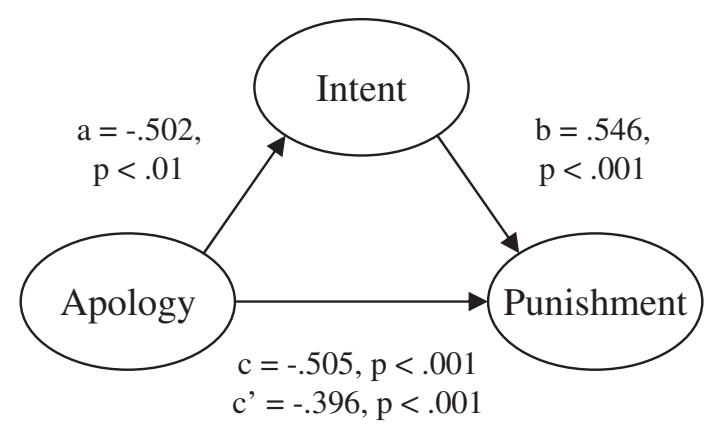

Moderation: $\quad x^{2}(1)=4.05, \mathrm{p}<.05$

Mediation: $\quad \mathrm{Z}=2.38, \mathrm{p}<.05$ 
The results also reveal significant main effects of apologies $\left(M_{\text {apology }}=2.09, M_{\text {no apology }}=2.37 ; F(1,212)=7.17, p<.01\right)$ and violation history $\left(M_{\text {repeat offense }}=2.41, M_{\text {first offense }}=2.06\right.$; $F(1,212)=11.58, p<.001)$ on perceived intent. Responses that included apologies or followed first offenses were perceived to be less indicative of harmful intent than responses without apologies or responses from repeat offenders. The apology $x$ violation history interaction had a marginal, but insignificant, effect on perceived intent $(F(1,212)=2.38, p=.12)$. Apologies influenced perceived intent when offered by repeat offenders $\left(M_{\text {apology }}=2.19, M_{\text {no apology }}=2.62 ; t=2.98, p<.005\right)$, but not when offered by first offenders $(t=0.82$, ns.). However, the low means across conditions suggest that, on average, participants did not perceive the offenses to be intentional.

The results also reveal significant main effects of apologies $\left(M_{\text {apology }}=2.69, M_{\text {no apology }}=3.27 ; F(1,212)=18.53, p<.001\right)$ and violation history $\left(M_{\text {apology }}=2.69, M_{\text {no apology }}=3.27 ; F(1\right.$, $212)=18.53, p<.001$ ) on need for punishment. Offenders were less likely to be punished when their responses included an apology or followed a first offense than they were when they did not apologize or they offended previously. The apology $\times$ violation history interaction was insignificant.

\section{Tests of moderated mediation}

For response appropriateness, the model for which the path from apologies to response appropriateness differed between conditions $\left(\chi^{2}(43)=90.42, p<.001\right)$ did not fit significantly better $\left(\chi^{2}(1)=.30\right.$, ns. $)$ than did the model with the effects of interest constrained to be equal between conditions $\left(\chi^{2}(44)=\right.$ 90.72, $p<.001)$. As in Study 2, violation history did not moderate the effect of apologies on response appropriateness. In both conditions, apologies had a positive effect on response appropriateness $(B=.579, p<.001)$ which decreased the need to punish the offenders $(B=-.633, p<.001)$. The direct effect of apologies on need for punishment $(B=-.505, p<.001)$ was reduced significantly (Sobel's $Z=4.05, p<.001$ ) and was no longer statistically significant $(B=-.147$, ns.) after controlling for response appropriateness. This result, illustrated in Fig. 3, replicates the Study 2 result that response appropriateness fully mediates the effect of apologies on need for punishment.

For perceived intent, the model for which the path from apologies to perceived intent differed between conditions $\left(\chi^{2}(43)=86.65, p<.001\right)$ fit significantly better $\left(\chi^{2}(1)=4.05\right.$, $p<.05)$ than the model with the effects of interest constrained to be equal between conditions $\left(\chi^{2}(44)=90.70, p<.001\right)$. Therefore, violation history moderated the effect of apologies on perceived intent. This effect was not supported by an ANOVA which does not account for measurement error. In the repeat offense conditions, apologies led to lower perceived intent $(B=$ $-.502, p<.01)$, which led to less need for punishment $(B=.546, p<.001)$. The direct effect of apologies on need for punishment $(B=-.505, p<.001)$ was reduced significantly by controlling for perceived intent (Sobel's $Z=2.38, p<.05$ ), but the effect remained statistically significant $(B=-.396$, $p<.001)$. Therefore, perceived intent only partially mediated the effects of apologies on the need to punish repeat offenders. In the first offender conditions, mediation was not supported because apologies did not affect perceived intent $(B=-.058$, ns.).

\section{Discussion}

This study replicates the Study 2 finding that response appropriateness fully mediates the effect of apologies on need for punishment. Therefore, findings from two studies support the notion that normative expectations favor the acceptance of apologies (Bennett \& Dewberry, 1994). In the present study, participants' agreement that less punishment is in order when apologies are offered is interpreted as an indication that they accepted the apologies.

In this study, perceived intent only partially mediated the effect of apologies on need for punishment, and this effect occurred only for less reputable (repeat) offenders. This finding of moderated mediation, but only partial mediation, raises doubts about perceived intent as a mediator of the effect of apologies on need for punishment. The perception that the offense was intentional was neither necessary nor sufficient to mediate the effect of an apology on the need to punish the offender.

\section{General discussion}

This research contributes to efforts to understand how firms or individuals can recover from their mistakes (e.g., Rotte et al., 2006). Three studies were conducted to shed light on how and when apologies work. The findings suggest that: (1) response appropriateness fully mediates the effect of apologies on need for punishment, (2) future expectancies only partially mediate the effect of apologies on need for punishment, but only for reputable offenders, (3) perceived intent only partially mediates the effect of apologies on need for punishment, but only for disreputable offenders, and (4) apologetic offenders are likely to avoid some consequences of their actions regardless of their reputability.

The findings that response appropriateness fully mediates the effects of apologies on the need for punishment and apologetic offenders face lighter punishment regardless of reputability is consistent with previous research. Goffman (1967) theorized a ritualized corrective cycle that includes an offer and an acceptance as important elements. If an apology is appropriate and one is offered, then the recipient is obligated to accept it (Bennett \& Dewberry, 1994). Darby and Schlenker (1989) found a significant main effect of apologies on punishment decisions, but no evidence that the offender's reputation moderates this effect. They interpret their finding as evidence of scripted responses to apologies that automatically benefit offenders who offer them. The present research extends these efforts by examining response appropriateness as a mediating variable and finding that it outperforms other potential mediating variables.

The finding that future expectancies only partially mediate the effect of apologies on need for punishment, and only when apologetic offenders are sufficiently reputable, suggests that assuring others of better behavior in the future is neither 
necessary nor sufficient for apologies to reduce the prospect of punishment. This finding is surprising considering the importance of deterrence as a justification for punishment decisions (McFatter, 1978). However, apologies also address other important justifications for punishment (Schlenker, 1980). The finding that perceived intent only partially mediates the effect of apologies on need for punishment, and only with apologies issued by disreputable offenders, suggests that apologies do not operate through their effects of perceived intentions. This finding is inconsistent with implicit theories that the intentions of offenders matter when making punishment decisions. It also contradicts the notion that reputable actors should benefit most from apologies. In the present study, reputable actors were assumed to have good intentions whether they apologized or not. As a result, apologies influenced perceived intent only for less reputable offenders. However, this effect may depend on the type of offense committed. In the present study, the mediating role of perceived intent was considered only when offenders committed ability-related violations. The effect may differ when offenders commit morality-related violations, thereby arousing suspicion in others (e.g., Main et al., 2007).

The present research also helps clarify the mixed results regarding reputability as a moderator of the effectiveness of apologies. In previous research, reputability has been shown to enhance the effects of apologies on some outcomes (e.g., Kim et al., 2004), but not others (e.g., Darby \& Schlenker, 1989). Studies also have produced mixed results regarding reputability as a moderator of the effect of apologies on a particular outcome (e.g., punishment). In the present research, reputability was shown to facilitate the effect of apologies on future expectancies, but inhibit their effects on perceived intent. This finding reflects a reversal of the effect of reputability as a moderator of the benefits of apologies. However, as discussed previously, this effect may be peculiar to certain types of violations. Reputability did not moderate the effects of apologies on response appropriateness or need for punishment.

This research has the potential to contribute to practice by shedding light on a rhetorical device that individuals often use to protect their firms or themselves from negative publicity (e.g., Monga \& John, 2008). Findings from three experiments suggest that apologies benefit offenders, regardless of their reputability. By contrast, Kim et al. (2004) suggest that there are limits to the effectiveness of apologies. In their studies, they found that apologies are less effective than denials for individuals suspected of morality-related trust violations, and they can backfire if individuals apologize for something they did not do. A major difference between the studies of Kim et al. and the present ones is that the guilt or innocence of offenders was unknown in the former case and assumed in the latter. Combined, the two sets of findings suggest that it is best to deny misdeeds if guilt cannot be proven, but apologize for them if guilt has been established. Moreover, if an individual is deemed responsible for an offense but there is ambiguity surrounding motive, it is safer to admit to a mistake than to confess to a misdeed.

Two aspects of the present investigation limit the generalizability of its findings to some business-to-consumer contexts.
First, although the scenarios portray the actions of service providers, the responses from research participants do not reflect the perspectives of consumers. Consumers are likely to be suspicious when they receive apologies from profit-seeking entities and their perceptions of the source and motives can affect the effectiveness of apologies (Darby \& Schlenker, 1982). Nonetheless, previous studies have found that apologies issued on behalf of organizations result in a variety of favorable responses from consumers (Blodgett et al., 1997; Smith et al., 1999). Second, the present research considered the effects of apologies on punitive responses only. Therefore, its findings may be limited to situations involving punitive responses like negative word-of-mouth communications (Blodgett et al., 1997). Future research is needed to examine mediators of the effects of apologies on positive outcomes like satisfaction (Smith et al., 1999) or future patronage (Blodgett et al., 1997).

\section{References}

Bennett, M., \& Dewberry, C. (1994). 'I've said I'm sorry, haven't I?' A study of the identity implications and constraints that apologies create for their recipients. Current Psychology, 13(1), 10-20.

Blodgett, J. G., Hill, D. J., \& Tax, S. S. (1997). The effects of distributive, procedural, and interactional justice on post-complaint behavior. Journal of Retailing, 73(2), 185-210.

Boulding, W., Kalra, A., Staelin, R., \& Zeithaml, V. A. (1993). A dynamic process model of service quality: From expectations to behavioral intentions. Journal of Marketing Research, 30(1), 7-27.

Darby, B. W., \& Schlenker, B. R. (1982). Children's reactions to apologies. Journal of Personality and Social Psychology, 43(4), 742-753.

Darby, B. W., \& Schlenker, B. R. (1989). Children's reactions to transgressions: Effects of the actor's apology, reputation, and remorse. British Journal of Social Psychology, 28, 353-364.

Ferguson, D. (2008). Golf Channel anchor Kelly Tilghman suspended two weeks for 'lynch' comment. www.StarTribune.com, January 10.

Frank, J. (2000). Sorry is no longer the hardest word. Marketing Focus. www. marketing.haynet.com/feature00/1012/; visited October 7, 2001.

Frieswick, K. (2001). Say you're sorry: In some lawsuits, falling on your sword may be smarter than wielding it. CFO.Com: Tools and Resources for Financial Executives, May 1, www.cfo.com/Article?article=2922, visited February 14, 2002.

Goffman, E. (1967). Interaction ritual. New York: Pantheon Books.

Goffman, E. (1971). Relations in public. New York: Basic Books.

Gold, G. J., \& Weiner, B. (2000). Remorse, confession, group identity, and expectancies about repeating a transgression. Basic and Applied Social Psychology, 22(4), 291-300.

Hosmer, L. T. (1995). Trust: The connecting link between organizational theory and philosophical ethics. Academy of Management Review, 20(2), 379-403.

Hung, I. W., \& Wyer, R. S., Jr. (2008). The impact of implicit theories on responses to problem-solving print advertisements. Journal of Consumer Psychology, 18(3), 223-235.

Kelley, H. H. (1967). Attribution theory in social psychology. In D. Levine (Ed.), Nebraska Symposium on Motivation, Vol. 15. (pp. )Lincoln: University of Nebraska Press.

Kim, P. H., Ferrin, D. L., Cooper, C. D., \& Dirks, K. T. (2004). Removing the shadow of suspicion: The effects of apology versus denial for repairing competence- versus integrity-based trust violations. Journal of Applied Psychology, 89(1), 104-118.

Lazare, A., (1996). Go ahead say you're sorry. Psychology Today, 28 (1), $40-43,76,78$.

Main, K. J., Dahl, D. W., \& Darke, P. R. (2007). Deliberative and automatic bases of suspicion: Empirical evidence of the sinister attribution error. Journal of Consumer Psychology, 17(1), 59-69.

McFatter, R. M. (1978). Sentencing strategies and justice: Effects of punishment 
philosophy on sentencing decisions. Journal of Personality and Social Psychology, 36(12), 1490-1500.

McShane, L. (2007). Imus's apology does nothing to quiet a chorus of critics. Washingtonpost.com, April 9.

Monga, A. B., \& John, D. R. (2008). When does negative brand publicity hurt? The moderating influence of analytic versus holistic thinking. Journal of Consumer Psychology, 18(4), 320-332.

O'Connor, C. (2004). Who's sorry now? An orgy of apologies spreading across the world. Denver Post, August 15, L1.

Ohbuchi, K., Kameda, M., \& Agarie, N. (1989). Apology as aggression control: Its role in mediating appraisal of and response to harm. Journal of Personality and Social Psychology, 56(2), 219-227.

Reeder, G. D. (1993). Trait-behavior relations and dispositional inference. Personality and Social Psychology Bulletin, 19(5), 586-593.

Reeder, G. D., \& Brewer, M. B. (1979). A schematic model of dispositional attribution in interpersonal perception. Psychological Review, 86(1), 61-79.
Reeder, G. D., \& Coovert, M. D. (1986). Revising an impression of morality. Social Cognition, 4(1), 1-17.

Rotte, K., Chandrashekaran, M., Tax, S. S., \& Grewel, R. (2006). Forgiven but not forgotten: Covert uncertainty in overt responses and the paradox of defection-despite-trust. Journal of Consumer Psychology, 16(3), 283-294.

Schlenker, B. R. (1980). Impression management: The self-concept, social identity, and interpersonal relations. Montery, CA: Brooks/Cole Publishing. Skowronski, J. J., \& Carlston, D. E. (1989). Negativity and extremity biases in impression formation: A review of explanations. Psychological Bulletin, 105(1), 131-142.

Smith, A. K., Bolton, R. N., \& Wagner, J. (1999). A model of customer satisfaction with service encounters involving failure and recovery. Journal of Marketing Research, 36(3), 356-372.

Walster, E. G., Walster, W., \& Berscheid, E. (1978). Equity: Theory and research. Boston: Allyn and Bacon. 